\title{
« Dans le sombre jardin » de Leopoldo María Panero
}

\section{François-Michel Durazzo}

\section{(2) OpenEdition}

Édition électronique

URL : http://journals.openedition.org/agedor/642

DOI : 10.4000/agedor.642

ISSN : 2104-3353

Éditeur

Laboratoire LISAA

\section{Référence électronique}

François-Michel Durazzo, « «Dans le sombre jardin » de Leopoldo María Panero », L'Âge d’or [En ligne], 7 | 2014, mis en ligne le 01 mars 2014, consulté le 01 mai 2019. URL : http://journals.openedition.org/ agedor/642; DOI : 10.4000/agedor.642 
François-Michel DURAZZO

Bordeaux, Lycée Camille Jullian.

\section{«Dans le sombre jardin » de Leopoldo María Panero}

Résumé : Pour dépasser certaines lectures de l'œuvre de Leopoldo María Panero, biaisées par le regard qu'a pu poser le cinéma sur sa famille, d'une part, par la biographie de l'auteur, d'autre part, presque toute sa vie enfermé dans différents hôpitaux psychiatriques, notre lecture, centrée sur l'étude du lieu récurrent et signifiant, qu'est le jardin, tente d'approcher le cœur ardent du poème : espace dans lequel se projette l'être-au-monde, dans l'irréconciliable amour-haine que le je voue à l'Autre.

Mots-clés : jardin - asile.

Resumen: Con el fin de superar ciertas lecturas de la obra de Leopoldo María Panero, sesgadas por la mirada que echaron las películas rodadas sobre su familia, por un lado, y, por otro, la biografía del autor encerrado la mayor parte de su vida en distintos psiquiátricos, nuestra lectura, centrándose en el estudio del lugar recurrente y significativo que representa el jardín, trata de acercarse al corazón ardiente del poema como espacio en el que se proyecta el ser-al-mundo, en el irreconciliable amorodio que el yo siente hacia el Otro.

Palabras clave: jardín - manicomio.

$\mathrm{I}$ l y a de cela une vingtaine d'années, stimulé par l'intérêt porté par Marie-Claire Zimmermann à la poésie de ceux que l'anthologie de José María Castellet avait consacrés comme les Novísimos, ${ }^{1}$ je traduisais deux recueils de Leopoldo María Panero, alors inconnu en France : Poemas del Maniconio de Mondragón et Poemas contra España y otros poemas no de amor, réunis sous le titre Dans le sombre jardin de l'asile.... ${ }^{2}$ À cette rencontre avec l'œuvre devaient succéder plusieurs visites à Mondragón, durant lesquelles j'eus l'occasion de me promener avec Leopoldo María Panero et d'enregistrer un long entretien dans le jardin de l'hôpital psychiatrique, où le poète jouissait d'un régime de semi-liberté qui lui permettait de sortir à peu près quand il le désirait. ${ }^{3}$ J'étais à cette époque en "quête d'une voix » pour reprendre quelques mots du titre de la belle thèse de Lina Iglesias, celle d'une voix bien réelle, certes, mais surtout d'une voix « de papier», la seule qui finalement nous restera de ce naufrage humain. C'est donc à titre de témoin de cette rencontre que j'interviens dans ce colloque, rencontre qui s'est poursuivie et, pour ainsi dire accomplie, dans la traduction.

\footnotetext{
${ }^{1}$ CASTELLET, José María, Nueve novísimos poetas españoles (Pedro Gimferrer, Leopoldo María Panero, José María Alvarez, Guillermo Carnero, Manuel Vázquez Montalbán, Antonio Martínez Sarrión, Félix de Azúa, Vicente Molina Foix y Ana María Moix), Barcelone, Carlos Barral, 1970.

2 PANERO, Leopoldo María, Dans le sombre jardin de l'asile..., traduit de l'espagnol par F.-M. Durazzo, coédition La Maison de la Poésie du Nord/Pas-de-Calais et les éditions du Noroît (Québec), 1994.

${ }^{3}$ L'ESTRACELLE, Nº 6/7, Automne-Hiver, 1994, Leopoldo María Panero, entretien avec F.-M. Durazzo.
} 


\section{La critique face au phénomène Panero}

La singularité de la famille Panero, dont la tragédie portée à l'écran ${ }^{4}$ a un moment figuré une société franquiste minée par la répression, sous les soubresauts du mayo francés, alors que le jeune Leopoldo María âgé de vingt ans publiait ses premiers textes, ${ }^{5}$ ne cesse de peser sur la critique. S'agissant d'aborder la poétique qui traverse l'œuvre de Leopoldo María Panero depuis ses débuts jusqu'à sa fin en 2014, on a souvent cherché quelques clés susceptibles de donner l'accès à sa poésie dans le désastre qui dresse l'ancien régime représenté par Leopoldo père (1909-1962), frère de Juan Panero (1903-1937), contre le nouveau, incarné par les fils du premier, tous trois écrivains comme leur père et leur oncle : Juan Luis (1942-2013), Leopoldo María (1948-2014) et Michi (1951-2004). Or, nos premiers débats ont suffi à montrer que l'intérêt souvent dévié de l'objet littéraire, el morbo et la fascination suscités par la figure du "poète maudit», ne faisaient que nous détourner de l'œuvre et de la fonction scripturaire d'une voix qui se manifestait avec des mots pleins de révolte et d'espoir, à côté de celles d'autres poètes de la même génération comme Pere Gimferrer ou Ana María Moix, les premiers à accueillir à Barcelone et à reconnaître le jeune Madrilène. Quelques années plus tôt, la mort du père phalangiste, autoritaire, alcoolique mondain, client assidu des maisons closes, parfois violent lorsque son jeune fils se rebellait, avaient laissé Felicidad Blanc totalement démunie face à ses fils rebelles qui, en adolescents tourmentés par la figure d'un père écrivain révéré et haï, incapables de trouver leur place dans ces dernières années du franquisme, allaient se livrer à tous les excès de la vie nocturne et de la drogue. En assignant, une fois de plus, à cette famille d'écrivains une fonction symbolique, ne risquerait-on pas de la sommer de justifier la liquidation de l'héritage de la dictature, la nécessaire transition, la compassion pour les victimes d'hier et pour ceux que les circonstances étaient sans doute propices à laisser pour compte?

Dans le but d'ouvrir de fructueuses pistes de réflexion sur le fait poétique, certains d'entre nous se sont intéressés à l'œuvre de Leopoldo María Panero au regard de son inscription dans l'Histoire et du climat intellectuel d'une époque marquée, d'un côté, par le militantisme communiste puis trotskyste, d'un autre, par la surveillance policière et les premières années d'internement auxquelles il fut soumis par sa mère Felicidad Blanc, devant les désastres de la drogue. J'aimerais proposer, pour ma part, quelques pistes différentes et apporter, à travers cette modeste contribution, le témoignage d'un lecteur de poésie française, qui ne peut éluder la question de la réception de cette œuvre, de ce côté des Pyrénées. Question qui, certes, intéresse les spécialistes de la poésie moderne de langue espagnole, mais aussi les lecteurs de poésie espagnole en traduction, sans que vienne biaiser leur lecture la dimension historicisante de l'œuvre, à laquelle s'attachent les hispanistes civilisationnistes. De fait, je ne crois pas que notre rencontre avec l'œuvre de Leopoldo María Panero se ferait de la même façon, si nous, lecteurs français, n'étions pas au préalable, comme Leopoldo María Panero lui-même, familiers de l'œuvre de poètes comme Nerval, Baudelaire, Rimbaud, de la littérature décadentiste d'un Huysmans ${ }^{7}$ et, à

\footnotetext{
${ }^{4}$ CHÁVARRI, Jaime, El desencanto, 1976 ; FRANCO, Ricardo, Después de tantos años, 1994.

${ }^{5}$ PANERO, Leopoldo María, Por el camino de Swan, Málaga, Librería Anticuaria El Guadalhorce, 1968.

${ }^{6}$ UTRERA, Federico, "[Selon Jaime Chávarri], Leopoldo tuvo la inteligencia y la lucidez, porque es un tío listísimo, de agarrarse a toda una escuela de pensamiento de origen francés, que estaba muy de modo en aquella época, no conocía casi nadie; era absolutamente exquisita, elitista y adecuada y fue lo que, en un momento dado, le colocó en la élite. Tuvo la capacidad de apostar por una moda, de formar parte de algo.» in Después de tantos desencantos: vida y obra poéticas de los Panero, Festival Internacional de Cine de Las Palmas de Gran Canaria, 2008, p. 87.

${ }^{7}$ PANERO, Leopoldo María, Palabras de un asesino, Madrid, Libertarias / Prodhufi, 1992, p. 11.
} 
l'occasion, de Mirbeau, qui dans Le Jardin des supplices (1899) place la cruauté des hommes, le meurtre, le besoin de tuer, au cœur de la condition humaine, sans oublier Antonin Artaud, souvent cité par Leopoldo María Panero, lui-même atteint d'une maladie paranoïde caractérisée par des hallucinations et des idées de persécution.

Finalement, il importe peu de savoir si, comme le laisse entendre son biographe Benito Fernández, Leopoldo María Panero «n'est pas plus fou que vous et moi », s'il fut un homme de lettres qui se serait glissé dans la peau du fou au point de rester prisonnier d'un personnage qui n'existerait que dans ses poèmes, ou si, à l'inverse, nous sommes véritablement en face d'un cas clinique, d'un "fou littéraire » comme le furent en leur temps Nerval, Maupassant, Hölderlin ou Artaud. Doit-on considérer ces phares comme des doubles panériens, ou voir en Leopoldo María Panero un Kafka poète qui, sans être psychologiquement malade, fouillerait la psychologie de personnages placés dans des situations extraordinaires, Kafka, dont Leopoldo María Panero écrivait à sa mère le 19 février 1969: «Me alegro por fin que hayas leído a Kafka : es el espíritu más cercano al mío que he encontrado y que a buen seguro encontraré, como quizá te habré dicho muchas veces, y lo que él escribió es justamente lo que yo desearía haber escrito ».

La voix, qui s'exprime dans les poèmes de Leopoldo María Panero et qui parfois se présente comme celle d'un fou, est-elle autobiographique ? Doit-on au contraire suspecter, chez l'auteur, une volonté assumée de fabriquer un personnage qui dit je, en cohérence avec une œuvre tout aussi préméditée ? En effet, si l'on laisse un instant de côté le contexte social et politique, dans lequel l'œuvre du jeune poète militant de la fin des années soixante surgit, on peut se demander si, au-delà du masque de poète maudit, rieur et provocateur, qu'on s'est plu à exhiber dans les médias, on ne se trouve pas face à une œuvre plus suivie qu'il n'y parait, qui a su au fil des ans, de poème en poème, tisser une trame beaucoup moins soumise aux aléas d'une maladie mentale qu'il n'y paraît de prime abord, et dont le vocabulaire, la rhétorique, les motifs récurrents assurent la cohérence, tout en ébauchant une parole, faussement chaotique et spontanée, qui porte bien au-delà des revendications politiques, morales et sociales de son temps.

En nous renvoyant constamment à d'autres textes que les siens - pris dans le domaine étranger de préférence à la tradition espagnole -, et au-delà, aux schémas mentaux qu'ils ont façonnés, la voix du grand lecteur que fut Leopoldo María Panero nous semble étrangement familière et insaisissable à la fois. Au lecteur de se ménager une entrée, soit du côté du " dissensus » en puisant dans tout ce qui exprime l'opposition, la fracture, la révolte du je contre le monde, soit du côté de la « dystopie » qui offre la facilité de pouvoir repérer quelques lieux panériens emblématiques, ambivalents et signifiants.

Parmi ceux-là, il est un topos qui parcourt toute l'œuvre de Leopoldo María Panero : le jardin, dont le premier trait est d'être un mot emprunté au français, pour désigner un lieu bien différent du patio espagnol, mais aussi un terme polysémique, qui semblerait faire aussi bien référence à la réalité la plus immédiate du pensionnaire de l'asile qu'aux jardins abandonnés, rêvés ou imaginaires, dont la littérature et les Écritures nous offrent une foule d'exemples. C'est donc en plaçant cette réflexion « Dans le sombre jardin » de Leopoldo María Panero, comme point focal et métaphore du lieu d'où jaillit la voix, que je vais tenter d'aborder la problématique qui nous est posée dans ce colloque sous la forme «Dissensus et dystopie ». 


\section{Le jardin comme lieu du dissensus}

À côté de la calle, autre lieu récurrent dans cette œuvre complexe, le jardin occupe une place de choix. Pour avoir déambulé avec Leopoldo María Panero dans les rues de Mondragón, qu'il croyait ou me disait peuplées d'ennemis, pour m'être aussi assis à ses côtés sur un banc du vaste jardin baigné de lumière de l'asile - celui de Mondragón n'a rien de sombre -, on peut avancer l'hypothèse que le référent le plus immédiat soit bien loin de rendre compte d'une expérience autobiographique. La poésie de Leopoldo María Panero est avant tout une poésie de l'expérience intérieure, une expérience du langage et par le langage. Si elle emprunte ses mots au réel, ils ne le désignent pas, contrairement à ce que pourrait laisser entendre un titre comme Poemas del manicomio de Mondragón. Certes, une ville est nommée, et dans celle-ci, un espace, le manicomio, qui lui-même vient prendre place dans l'espace littéraire.

Bien que, de façon générale, on soit en droit d'émettre les plus grandes réserves sur l'authenticité des titres donnés par Leopoldo María Panero à ses recueils, de même que sur l'ordonnancement des textes à l'intérieur des recueils, à une époque où le poète envoie sporadiquement une poignée de feuillets dactylographiés sans ordre à l'éditeur qui le sollicite, il n'en reste pas moins que Leopoldo María Panero paraît scénariser le poème, l'inscrire dans un espace au référent identifiable pour dire autre chose que la vie, les pensées ou les rêves du fou qu'il incarnerait aux yeux du public.

Mieux comprendre la poésie de Leopoldo María Panero et le traitement dont le jardin y fait l'objet requiert au préalable une incursion dans l'un de ses textes, composé à Paris, les plus autobiographiques - ou autofictionnels ? - qui, s'ils ne constituent pas la matrice du poème à proprement parler, disent quelque chose du pré-poème, de la pensée qui soustend certains poèmes.

Lo que empecé a descubrir en aquella habitación de la rue Montorgueil, puede alguna vez ser usado para honor y mejoramiento de este jardín tan triste que habitamos, de esta naturaleza que los hombres odian hoy, sólo quizás, porque les ama. Pero en cualquier caso es evidente que es esa luz que al cerebro le falta, lo que buscamos toda nuestra existencia, poniéndole, eso sí, a nuestro deseo el tapujo de todos los hombres de la gloria y el poder; eso sí, esa luz que en algunos es naufragios, esa luz que a veces explota en la locura, lo que siendo allí precio de deshonra, es sin embargo en todo otro lugar de lo humano meta y esperanza secreta de una vida que perdimos todos nosotros en la infancia. ${ }^{8}$

En quelques mots, tout semble avoir été dit par l'assassin que Leopoldo María Panero prétend être, durant ces années où il répète à qui veut l'entendre qu'il a tué un homme. Curieusement, le jardin, tout en faisant référence à l'Eden, à l'espace primordial, ne se présente pas ici comme un lieu onirique, un paradis d'où l'homme aurait été expulsé, mais comme la métaphore d'un monde en ruine, un jardin triste, que double le mot naturaleza, en référence à une nature rousseauiste, originellement pure puis dévoyée, détournée de son sens, corrompue et plongée dans les ténèbres de la haine. La haine comme réponse à l'amour. Dissensus. Lieu dans lequel l'enfant se retourne contre sa mère, dont l'amour lui a signifié son abandon, et passage de l'obscur matriciel à la lumière aveuglante du jardin, où l'être poursuit sans fin les ténèbres lumineuses du giron de la nature, lumière inaccessible renvoyant aux naufragios, à la locura et, finalement, à la deshonra.

\footnotetext{
${ }^{8}$ Ibid., p. 62-65.
} 
Dans ses textes autobiographiques, ses nombreux entretiens, Leopoldo María Panero ne se contente pas de ronger sans fin son amertume et ses reproches vis-à-vis de sa famille et de la société, dont les lettres à sa mère Felicidad Blanc garderont la trace. Au-delà de références ambivalentes à l'imaginaire judéo-chrétien qui saturent les poèmes - à un Eden dont on aurait renversé la signification en le transformant en lieu d'exil ou d'enfermement -, cet extrait prélude à l'exaltation d'un moi qui se perd dans un tout. Rares sont les textes dans lesquels Leopoldo María Panero a été aussi explicite à ce sujet. Le je se dissout dans un todos nosotros, une humanité qui, pour une fois, ne semble pas avoir pas perdu tout espoir: meta y esperanza secreta, malgré sa mise en échec : naufragios, locura, deshonra; aussi le nœud de ce passage repose-t-il sur l'antithèse amour-haine, dans esta naturaleza que los hombres odian, sólo quizás, porque les ama.

De l'amour naît la haine, de la haine naît l'amour. «L'ange éveille l'appétit sombre du viol : le démon le vertige de l'unité. C'est qu'en fait une seule voie est ouverte à l'être : la chute... » déclare Pierre Emmanuel dans un chapitre «La mystique du gouffre », de son célèbre essai chez Baudelaire.' Chez Leopoldo María Panero, le désir frustré, interdit, à l'origine du mal, transforme, cette fois, la pure figure maternelle, l'ange incestueusement désiré, en cafard aux yeux bleus, expression oxymorique qui traduit l'ambivalence des sentiments qui unissent deux chants qui s'enchâssent dans le poème, sans parvenir à dialoguer. C'est à peine si le chant du poème porte le chant de la mère.

\section{La maldad nace de la supresión hipócrita del gozo}

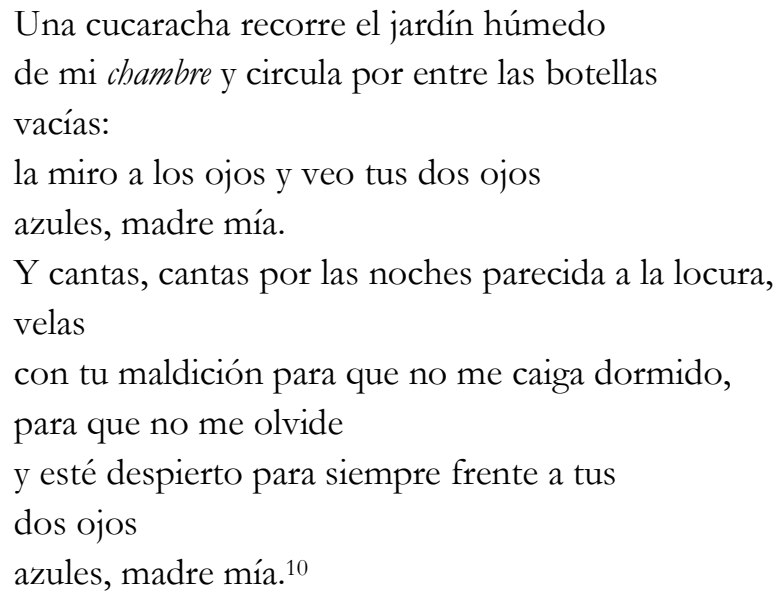

L'association chambre - en français dans le texte -, et jardin - emprunt au français -, évoque la «chambre jardin» de Baudelaire dans l'île Saint-Louis que ce dernier confie à Charles Asselineau avoir choisie «afin de ne voir que le ciel». La référence au Baudelaire des Fleurs du mal, ${ }^{11}$ entre autres réminiscences, se confirme par la suite : le jardín búmedo, placé en fin de vers, pour laisser place à un silence suggestif avant «la chambre », au vers suivant, désigne l'obscur lieu du désir, peut-être le sexe féminin, de même que le flacon, la botella vacía suggère l'ivresse. La cucaracha - métamorphose kafkaïenne - ne fait pas

\footnotetext{
${ }^{9}$ EMMANUEL, Pierre, Bandelaire, la femme et Dieu, Paris, Éditions du Seuil, 1982, p. 65.

${ }^{10}$ PANERO, Leopoldo María, Narciso en el acorde último de las flautas (1979), in Poesía 1970-1985, Madrid, Visor, 1993, p. 162.

${ }^{11}$ BAUDELAIRE, Charles : «Le tonnerre et la pluie ont fait un tel ravage, / Qu'il reste en mon jardin bien peu de fruits vermeils. » «L'Ennemi », Les Fleurs du mal, «Spleen et idéal », X, Paris, Gallimard, col. Le livre de Poche, 1964, p. 26.
} 
directement référence à la mère, pas plus que les yeux de l'immonde insecte ne sont ses yeux : La phrase : la miro a los ojos y veo tus dos ojos se présente plutôt comme la transcription consciente d'une hallucination - miro... veo... - et d'un objet de surprise, si l'on prête attention au rejet de l'adjectif azules, qui intervient comme une information secondaire, une fois identifiés les yeux de la mère, madre mía, expression fonctionnant simultanément comme une apostrophe et une exclamation. Dans la deuxième partie du poème introduit par la conjonction $y$, la femme-mère berce, veille son enfant malade $-Y$ cantas, cantas, por las noches... velas - sans être, une fois encore, directement associée à la locura, dont elle n'a que l'apparence... Or la fonction de la berceuse subit un renversement, le regard censé apaiser se fait insistant, gardant le je en éveil et l'empêchant de dormir. Trois subordonnées finales : para que no me caiga dormido (1), para que no me olvide (2) y esté despierto para siempre (3) développent la fonction phatique du regard qui maudit.

Malgré sa cohérence, ce type d'énoncé pose souvent problème au commentateur. Certains critiques, peut-être embarrassés par l'interprétation des textes panériens, ont cru possible, comme le fait Joaquín Ruano, auteur d'une thèse sur l'œuvre de Leopoldo María Panero, de les affilier à un surréalisme plus ou moins assumé : «La orientación que Panero da al surrealismo está dirigida hacia una parte muy específica del sueño: la pesadilla. Es el caso de "Linterna China", del poemario Narciso en el acorde último de las flautas »". À cela, on pourrait faire objecter à Paul Éluard, en désaccord déclaré avec André Breton, dans une célèbre introduction à l'un de ses premiers recueils ceci :

Il est extrêmement souhaitable qu'on n'établisse pas une confusion entre les différents textes de ce livre : rêve, textes surréalistes et poèmes. Des rêves, nul ne peut les prendre pour des poèmes. Ils sont, pour un esprit préoccupé de merveilleux, la réalité vivante. Mais des poèmes $[. .$.$] il est indispensable de savoir qu'ils sont la conséquence d'une volonté assez bien$ définie, l'écho d'un espoir ou d'un désespoir formulé.13

Faute d'un titre programmatique, ce poème aurait peut-être pu se présenter comme l'écriture d'une vision cauchemardesque. Or la maldad, la méchanceté qui résulte de son pendant - la maldición - trouve son origine, nace, d'une castration : la supresión del gozo ; le je se trouve renvoyé au vide, non pas à celui d'un Eden dont il aurait été expulsé, mais d'une prison-jardin dont le plaisir a été chassé et où il invoque, de façon répétée et quasi haletante, la figure maternelle désirée : tus dos ojos / ąules, madre mía. Si certains éléments : la nuit, la chambre, la présence obsédante des yeux bleus, la mère associée au cafard, semblent emprunter leur vocabulaire à la transcription d'un mauvais rêve, le titre dément une telle interprétation, en introduisant dans ces vers ce que Éluard appelle « l'écho d'un désespoir ».

Par ailleurs, Leopoldo María Panero n'a jamais été un homme d'écoles, ni de frontières - si ce n'est pour les transgresser -, comme d'ailleurs bon nombre de novísimos. Faisant feu de tout bois, mobilisant courants et contre-courants pour les subvertir, il agrège formes et motifs poétiques pour servir une esthétique composite de l'étrange, de l'esperpéntico, jusqu'à investir et recycler les traditions les plus anciennes. Tel est le cas, dans Mi madre, du genre arabo-andalou de la rawdiyyat (de rawd = jardin) dont les topoï - manojo de flores, corcel, caballero, jardín, estrellas, rosa, diadema... - viennent s'agréger au cliché de la sérénade, ou du rendez-vous nocturne au jardin, bien que la rencontre des amants n'ait pas lieu dans le poème, où le je se contente d'inviter la femme aimée à le rejoindre dans le

\footnotetext{
${ }^{12}$ RUANO, Joaquín (York University), « Sabotaje y transgresión. El espíritu de las vanguardias en la poesía de Leopoldo María Panero », Anuario Brasileño de Estudos Hispánicos XIX, Madrid, 1990, p. 33.

13 ÉLUARD, Paul, «Prière d'insérer au recueil Les dessous d'une vie ou La pyramide bumaine (1926). O.C., Paris, Gallimard, coll. La Pléiade, Tome I, 1977, p.1388.
} 
jardin: «escucha», "sal al jardín». Ici intitulé «Mi madre», le texte subvertit l'esprit de la rawdiyyat en substituant la mère à l'amante et l'enfant au chevalier.

$$
\begin{gathered}
\text { Mi madre } \\
\text { (reivindicación de una hermosura) }
\end{gathered}
$$

Escucha en las noches cómo se rasga la seda

y cae sin ruido la taza de té al suelo

como una magia

tú que sólo palabras dulces tienes para los muertos

y un manojo de flores llevas en la mano

para esperar a la Muerte

que cae de su corcel, herida

por un caballero que la apresa con sus labios brillantes

y llora por las noches pensando que le amabas,

y dice sal al jardín y contempla cómo caen las estrellas

y hablemos quedamente para que nadie nos escuche

ven, escúchame hablemos de nuestros muebles

tengo una rosa tatuada en la mejilla y un bastón con

empuñadura en forma de pato

y dicen que llueve por nosotros y que la nieve es nuestra

y ahora que el poema expira

te digo como un niño, ven

he construido una diadema

(sal al jardín y verás cómo la noche nos envuelve).14

Point de fixation du désir incestueux, le jardin est le lieu primordial, la matrice. C'est du moins sous cet éclairage que Leopoldo María Panero semble placer en citant une fois de plus quelques mots français qui, cette fois, renvoient à un poète qui exercera une influence décisive sur la construction panérienne de la figure d'un grand poète maudit :

He matado he

$$
\begin{array}{r}
\text { Vallados en el Jardin des Plantes, rejas } \\
\text { que prohíben la fuente } \\
\text { "j'ai tué l'esprit» }
\end{array}
$$

$$
\text { matado matado }
$$

he matado a mi madre en el Jardin des Plantes.

No supo decir que Dios es mujer, ni qué Dios

Era yo. ${ }^{15}$

Ces vers semblent se faire l'écho d'une lecture des Cabiers du retour à Paris d'Antonin Artaud, à une époque où, à un an d'intervalle, le poète malade et interné dicte à Paule Thévenin quelques-uns des textes bouleversants, qui ont marqué Leopoldo María Panero.

Moi, M. Antonin Artaud, né le 4 septembre 1896 à Marseille, 4, rue du Jardin-des-Plantes, d'un utérus où je n'avais que faire et dont je n'ai jamais rien eu à faire même avant. ${ }^{16}$

14 PANERO, Leopoldo María, Poemas del manicomio de Mondragón, Madrid, Hiperión, 1987, p. 41.

15 PANERO, Leopoldo María, El último hombre (1983), in Poesía 1970-1985, op. cit., p. 239. 
Le « tu n'es pas encore là » s'adressant à la forme et mon intensité de colère est idiot car moi je suis là si je ne peux retrouver mon ton exact et avoir visionné ceci du Saint-Esprit est un arbitraire ramené après car c'est avec ça que j'ai tué l'esprit : la colère esprit ton, douleur et non fait. ${ }^{17}$

Les Cabiers d'Artaud, sous forme de notes à peine intelligibles, pleins de colère et de révolte, subissent dans l'œuvre de Leopoldo María Panero, loin d'être si crû, un traitement métaphorique qui, malgré la haine, n'exclut ni le désir, ni l'amour. L'« utérus où je n'avais que faire » prend chez Leopoldo María Panero la forme d'une source interdite, entourée de "vallados, de rejas, que probíben la fuente. »

Encore une fois, le jardin n'est pas le paradis dont le je a été expulsé, ou plutôt il cesse d'être la matrice d'où celui-ci a été chassé, cet agujero llamado nevermore, ${ }^{18}$ pour devenir le lieu auquel l'enfant - l'éternel enfant qu'est Peter Pan - se voit un moment refuser l'accès. Por fin la abre, y entra Peter Pan (el mismo adolescente que habíamos visto en la secuencia i tratando inútilmente de penetrar en el jardín). ${ }^{19}$ Cependant, le lieu dont il ouvre la porte, dans lequel il pénètre, se révèle un non-jardin, un anti-Eden, un enfer de solitude. «En fin, ahora sabría cuál era el precio actual del héroe o del genio: la más irremediable soledad; cerré pues los ojos para guardar aún mejor ese jardín de mi mente que nadie, salvo Pierre Dumont, osó nunca hollar $»^{20}$.

C'est que le jardin de l'esprit est intérieur, un jardín para el odio [...] una jaula de cristal ${ }^{21}$ dans laquelle le je se trouve à la fois exposé aux regards, transparent et invisible - d'où la haine - enfermé dans un lieu dont la barrière est l'interdit; il est un lieu d'exil, où prend forme la condamnation du désir et de la jouissance, niée au poète-enfant que, si l'on en croit un sonnet de son père, Leopoldo María devait rester toute sa vie, accomplissant ainsi à la fois une prédiction et une malédiction ${ }^{22}$. Rien d'étonnant alors que le jardin se double de lieux réels : lieux de la représentation, où l'on se montre, qu'il s'agisse de celui de l'asile, ou de celui du jardin du Lycée italien qui sert de cadre au Desencanto, au n ${ }^{\circ} 1$ de la Calle Agustín de Betancourt, Lycée italien qu'ont fréquenté les trois frères, et dans la cour duquel le jeune Leopoldo María passe de longues et heureuses heures à lire : «no me daban la penitencia, ni nada $»^{23}$.

Cependant, la présence obsédante de la figure maternelle - la mère réelle, Felicidad Blanc, rendue tant de fois responsable de l'internement, de la solitude et de la relégation de son fils poète - n'efface pas du jardin panérien l'ombre du père-poète. En réaction à la

16 ARTAUD, Antonin, Cabiers du retour à Paris, du 7 septembre 1945, in O.C., Paris, Gallimard, 1956, p. 51-52.

${ }^{17}$ Ibid., Août- septembre 1946, p. 240.

18 Titre de l'anthologie de Leopoldo María Panero sous-titrée (Selección poética, 1968-1992) éditée par Jenaro Talens pour la collection des «Letras hispanicas » des éditions Cátedra. L’expression agujero llamado nevermore est extraite d'un poème de Teoría (1973), écrit dans la période poundienne de Leopoldo María Panero, p. 52 de l'édition de Huerga y Fierro, Madrid, 2002.

${ }^{19}$ PANERO, Leopoldo María, En lugar del bijo (1976), in Cuentos Completos, Madrid, éd. Páginas de Espuma, 2007, p. 158.

${ }^{20}$ PANERO, Leopoldo María, Palabras de un asesino, op. cit., p. 82.

${ }^{21}$ PANERO, Leopoldo María, Danza de La Muerte, Montblanc (Tarragone), Igitur Ediciones, 2004, p. 57.

22 PANERO, Leopoldo, «El distraído (Retrato de Leopoldo María) ». El niño distraído está en su sueño / (surcador de la vida transparente) / copiando de memoria, con la frente / dormida; seria el alma y él risueño. // Su mano que dibuja pone empeño / de realidad en el papel viviente, / y el balar de la oveja tibio siente / mientras lo grande evoca en lo pequeño. // Su dibujo nos da, casi seguro / de sí mismo, y su mano creadora / tiende, recién del éxtasis salida; / / baña la creación su rostro puro, / y un dibujo infantil parece ahora, / él, que un niño será toda la vida. O.C. 1, Poesías: 1928-1962, Madrid, éd. Nacional, 1973, p. 558.

${ }^{23}$ Entrevista a Leopoldo María Panero, Café-con-letra.blogspot.fr, Gandía, Valence, mars 2008. 
lecture d'«En las manos de Dios », ${ }^{24}$ poème de Leopoldo Panero assez conventionnel, consacré à une vieille femme qui vendait des marrons chauds sur la Plaza Mayor de Madrid, et qui n'est pas sans rappeler au lecteur français «Le mendiant $»^{25}$ de Victor Hugo ou «Les Effarés $»^{26}$ d'Arthur Rimbaud, Leopoldo María Panero nous offre l'un des rares textes qui fassent dialoguer et unissent leurs deux ouvres dans une même compassion pour les déshérités. La réponse du fils ne s'oppose pas d'emblée violemment au père, mais renchérit (también), avant de lui donner une réponse cinglante. De la Plaza Mayor nous voici transportés à l'asile, et au "pays des merveilles » d'Alice, où nous est proposée une morale de substitution à celle du père, une «morale du désastre ».

\author{
Infierno y paraíso \\ “Allí estará también la castañera \\ de ocho pares, \\ y el humo de los céntimos, / y el vaho en los bolsillos." \\ Leopoldo Panero, Escrito a cada instante
}

Pero no sólo los mendigos, padre, van al paraíso

van también aquellos que aun más asco dan

también estos mendigos del ser que acezan

a la puerta del manicomio

esas caricaturas humanas, tal como esta

que Alicia se piensa en el

jardín no

humano de las flores

y quisiera destruir el universo

porque si hay algún monstruo, éste es la desgracia

y la única injusticia que existe es la injusticia evidente

y si hay alguna moral, ésta es la moral del desastre. ${ }^{27}$

\title{
Le jardin comme expression d'une dystopie
}

\footnotetext{
24 PANERO, Leopoldo María, "En las manos de Dios », Alli estará también la castañera / de ocho pares, y el bumo de los céntimos, / y el vaho en los bolsillos, y los ojos / menudos, y el rescoldo retirado / de mucha soledad en este mundo. / Alli estará caliente en sus inviernos, / con la Plaza Mayor de sus pupilas / intensamente sola. Alli sus hombros / ladeados, su pañuelo en la cabeza, / dulcemente estarán, al fin sin nadie / fugaz en torno suyo. Se llamaba / Macaria, lo recuerdo fijamente, / igual que si las letras fueran brasas / dentro del corazón. La vi más tarde / mendigando en las calles, ya en el limite / inútil de sus pies y de sus manos, / sin poderse valer de su mirada. / tropezando en la luz de las esquinas, / acostada en las puertas, dulce piedra / de sufrimiento... Y estará sentada / a la diestra del Padre, y no habrá nieve, / ni cellisca perpetua contra el rostro / cansado del domingo. Y siento aquella / sonda corazonada que sentía / al toparla de vieja, cuando estaba / desprendiéndose ya de su ternura / igual que el musgo de la piedra búmeda; / siento aquel mismo límite de hermano, / de prójimo nevado inmóvilmente... in Escrito a cada instante (Premio Nacional de Literatura), Madrid, Cultura Hispánica, 1949.

${ }^{25}$ HUGO, Victor, Les Contemplations, Livre cinquième, IX (1856) Paris, Gallimard, coll. Folio, 2002, p. 346.

${ }^{26}$ Le jeune poète envoie ce texte à Jean Aicard en 1871.

27 PANERO, Leopoldo María, Guarida de un animal que no existe, Madrid, Visor, 1998.
} 
Si le jardin est le lieu où se joue le dissensus, il est aussi celui d'une dystopie. Or Claudie Terrasson a d'emblée averti : il ne s'agit pas de prendre le mot «dystopie » au sens usuel qu'il a dans le roman d'anticipation pour nommer une utopie qui vire au cauchemar, comme dans les Animaux de la Ferme, ou une contre-utopie, comme dans Le Meilleur des mondes.

Quoique le titre du recueil intitulé Poemas del manicomio de Mondragón ${ }^{28}$ ne soit pas une idée de Leopoldo María Panero lui-même, mais de Jesús Munárriz, force est - nous avons déjà insisté sur ce point - d'accepter la façon dont sa signification résonne dans tout le livre, voire au-delà. Dès le premier texte, le décor semble planté. Le lieu emblématique de l'hôpital est cet obscuro jardín del manicomio, ${ }^{29}$ manicomio auquel le titre appose le nom d'une ville, qui à aucun moment n'est citée dans la suite du recueil. Or, ce qui frappe le plus le visiteur naïf du poète interné à Arrasate-Mondragón, au cœur des montagnes de la Guipuscoa, c'est précisément la luminosité, la clarté, la grandeur d'un jardin bien entretenu, certes sans luxuriance excessive - point de fleurs rares ni abondantes - mais assez vert pour ne pas détonner dans une ville basque aux balcons ordinairement fleuris. Aussi la mention de Mondragón apparait-elle comme un procédé plutôt grossier, dans le but évident d'orienter la lecture de façon racoleuse. Tout se passe, en effet, comme si, à l'instar des critiques auxquels nous avons fait allusion en ouverture, l'éditeur avait voulu jouer sur la curiosité malsaine d'un certain type de lecteurs, curieux de détails croustillants et atroces de la vie du poète-fou sur laquelle Chávarri a, le premier, attiré l'attention, avant Ricardo Franco.

Laissons de côté cet aspect pour nous concentrer sur le titre réparateur, choisi en accord avec Leopoldo María Panero pour l'édition française : Dans le sombre jardin de l'asile, et sur les premiers vers du recueil:

En el obscuro jardín del manicomio

Los locos maldicen a los hombres

Las ratas afloran a la Cloaca Superior

Buscando el beso de los Dementes.

Dès le vers incipit, l'épithète obscuro accolé au jardín enlève toute possible valeur référentielle au jardin de l'asile Mondragón. Si le jardin du poème est obscur, c'est qu'il désigne un tout autre lieu, qui porte l'empreinte d'une souillure originelle. Origine de toute condition humaine, il figure aussi son lieu ultime : la cloaca, le lieu dans lequel l'homme qualifié de demente $e^{30}$ - se trouve littéralement dépossédé de son esprit et accomplit son destin de rata. C'est aussi, pour reprendre le titre du premier recueil de nouvelles de Leopoldo María Panero, el lugar del hijo, ${ }^{31}$ le lieu de l'être qui se définit d'abord par sa filiation, nous l'avons vu, conflictuelle. Loin de ressembler à un jardin lumineux, aveuglant, celui du poème est devenu un lieu de mort, d'où tout bonheur est banni. Nous sommes assez loin du «jardin noir» d'Artaud, ${ }^{32}$ qui doit son obscurité à la nuit, fût-elle une nuit

\footnotetext{
28 PANERO, Leopoldo María, Poemas del manicomio de Mondragón, op. cit.

${ }^{29}$ Ibid., p. 13.

${ }^{30}$ Cf. ce que Leopoldo María Panero appelle la desterritorialización dans l'article, "Dolor real y sufrimiento imaginario", Revista de la asociación española de Neuropsiquiatría, n 3, janvier-avril 1982.

31 PANERO, Leopoldo María, El lugar del bijo, Barcelone, Tusquets, 1976, où le narrateur évoque el presentimiento de la locura. p. 47.

32 ARTAUD, Antonin, "Jardin noir»: «Roulez fleuves du ciel dans nos pétales noirs. / Les ombres ont comblé la terre qui nous porte. / Ouvrez nos routes au charroi de vos étoiles. / Éclairez-nous, escortez-nous de vos cohortes, / Argentines légions, dans la route mortelle / Que nous entreprenons au centre de la nuit. /
} 
métaphorique de l'angoisse, une "nuit obscure de l'âme ». L'obscurité du jardin panérien serait plutôt celle d'un enfer, non pas un Enfer à la manière de Dante, qui consisterait à paquer les damnés selon leurs péchés, non pas celui des «essences» ou des «espèces nosographiques", évoqué par Foucault, ${ }^{33}$ pour qui la psychiatrie, dans une approche clinicienne héritière de Sydenham et de la pensée de Descartes sur la relégation des «insensés », a longtemps considéré qu'elle avait affaire à des maladies dont le sujet était l'hôte plutôt qu'à des individus, mais l'enfer - ou le «cloaque» - auquel l'homme est universellement condamné dès lors que sa conscience s'éveille au monde de façon aiguë. De sorte que Ello prueba que el destino de las ratas / Es semejante al destino de los hombres, ${ }^{34}$ deux vers dont on peut inverser sujet et prédicat : le destin des hommes est semblable à celui des rats.

L'espace intérieur de Leopoldo María Panero - que la psychiatrie définirait comme paranoïaque - s'objective dans le texte, définit un espace littéraire, en empruntant à la langue les mots qui nomment les lieux d'enfermement - prison, asile et couloirs -, pour les peupler d'une inquiétante faune - cafards, araignées, rats, tortues, loups -, de déshérités et d'exclus - fous, mendiants, marginaux, indociles, assassins, drogués, homosexuels ${ }^{35}$ révolutionnaires, judas, Lamed Wufnik, ${ }^{36}$ voire certains êtres paradigmatiques réduits à l'épaisseur d'une ombre, ${ }^{37}$ à celle d'un monstre d'argile comme le Golem, que ne rassemble que l'opposition à la société et à l'État, ${ }^{38}$ considérés comme intolérants, répressifs, conformistes, aux bourgeois, étriqués et incapables de proposer la moindre issue à la figure.

De fait, le seul lieu susceptible d'exalter cette galerie de portraits, d'apporter à ceux-ci statut et reconnaissance, serait l'espace littéraire, espace rarement nommé en tant que tel, mais partie prenante d'une réalité plus vaste que constituerait la création sous toutes ces formes, espace signifié, métaphorisé, à l'aide de différentes reprises lexicales dont la plus féconde est peut-être le mot jardin. Parmi ces figures, le fou, à l'occasion el loco al que llaman el Rey, ${ }^{39}$ endosse la figure panérienne de l'homme et du poète :

\footnotetext{
Ainsi le jardin parle au bord de la marée. / Et le métal figé de vos saintes colonnes / Ô tiges a vibré. Voici la nuit qui donne / L'universelle clef de ses portes de corne / Aux émanations des âmes délivrées. » O. C., Paris, Gallimard, coll. La Pléiade, 1956, p 214.

33 PANERO, Leopoldo María, in "Dolor real y sufrimiento imaginario", op. cit. : Lo que Foucault llamaba el jardín de las especies nosográficas...

34 PANERO Leopoldo María, Poemas contra España y otros poemas de amor, Madrid, Libertarias / Prodhufi, 1990.

${ }_{35}$ Cf. « Majestad última de los pédés»: Nefasto arregla su jardín / Bajo la luz de aplomo, PANERO, Leopoldo María, Teoría, Madrid, Visor, 1972, p. 102.

${ }^{36}$ Les Lamed Wufnik - Lamed was chez André Schwarz-Bart dans Le Dernier des Justes - tirent leur nom de la valeur numérique des lettres hébraïques lamed (30) et vav (6). Ce mot yiddish désigne donc les trente-six justes qui existeraient sur terre, tous pauvres, inconnus et persécutés. Selon la tradition rapportée par Max Brod, la source de Borges, ils doivent ignorer leur identité mystique et meurent en l'apprenant. André Schwarz-Bart, dans Le Dernier des Justes (1959) en revanche, signale seulement que "souvent ils s'ignorent eux-mêmes ». Ces “justes" sont en quelque sorte la conscience de l'humanité : «s'il venait à en manquer un seul, la souffrance des hommes empoisonnerait jusqu'à l'âme des enfants ».

${ }^{37}$ Cf. «Himno a Satán (2a versión) » : La grandeza del lobo / no es penumbra / ni aire / es solo el fulgor de una sombra I de un animal herido en el jardín / de noche, mientras tú lloras / como en el jardín de un animal herido. in PANERO, Leopoldo María, Orfebre, Madrid, Visor, 1994, p. 20.

38 PANERO, Leopoldo María, Poemas contra España y otros poemas de amor, op. cit.

${ }^{39}$ Ibid., p. 25.
} 
Un loco tocado de la maldición del cielo

Canta humillado en una esquina

Sus canciones hablan de ángeles y cosas

Que cuestan la vida al ojo humano

Quatre vers semblent donner ici la clé du recueil tout entier : la condition humaine procède $d u$ ciel, d'un au-delà, d'une figure présentée non pas comme transcendante mais j'oserais dire - originelle et parentale, sans qu'on puisse pour autant lui conférer un sens sacré, puisqu'il impose au sujet une malédiction. Celle-ci, en touchant l'être, le relègue dans un coin. Dès lors, humilié, le fou n'a plus d'autre recours que son chant; il chante en aède la geste des humiliés. Sa voix choisit le mode mineur. Humble, elle murmure des chansons, pleine d'anges qui peuplent le ciel d'où elle a été expulsée, mais aussi des « choses qui coûtent la vie à l'œil humain », expression énigmatique que ne vient pas clairement expliciter les autres textes du recueil, sans pour autant résister à l'interprétation. Quelles pourraient être en effet ces choses qui nous aveuglent, si ce n'est la vérité. Cette même vérité à laquelle, dans un article déjà cité, Leopoldo María Panero attribue son enfermement dans le «jardin des horreurs ».

Mi sinceridad a veces brutal, hinchada por lo que Baudelaire llamaba "la verdad grotesca del alcohol" ${ }^{40}$ es lo que me ha recluido aquí, en este manicomio de muertes y resurrecciones, en este jardín de los horrores, donde no sólo [...] se nos trata como una suerte de gallinas ponedoras, como si no existiéramos que es la etimología de la palabra esquizofrenia, la extranjeridad del sujeto. ${ }^{41}$

Désindividué par la psychiatrie, c'est-à-dire la société dont l'espace tout entier se trouve finalement réduit à «l'obscur jardin de l'asile », le sujet acquiert l'insignifiance d'un Golem évoqué en ces termes par Leopoldo María Panero dans un de ses articles de presse :

Dicen que cada veinte años, en el ghetto judío de Praga aparece un hombre que es todos los hombres; dicen que cada veinte años se tiene miedo de ver a un hombre... Por la mañana, en el jardín donde aún muere, se escucha a los pájaros decir para su nombre: y el agua cae y lo borra. Porque este hombre tuvo alguna vez un nombre, y fue un pie sobre la tierra, pero ya no lo tiene. 42

Le Golem - en hébreu : גולם «embryon » - est, dans la mystique juive de tradition yiddish, un personnage légendaire ressemblant vaguement à un être humain. Privé de conscience et de libre-arbitre, réduit au silence, il est, en quelque sorte, la marionnette de son créateur. Sur son front, celui-ci a écrit le mot émeth - en hébreu : אמת , la "vérité 》mais, dès la première lettre effacée, le mot émeth devient meth - en hébreu מת, la «mort». Que le je se définisse comme un zombie, un mort-vivant ou une ombre, sa condition est d'être voué à l'anéantissement, d'être empalé en uno de los barrotes del jardín... ${ }^{43}$

\footnotetext{
${ }^{40}$ Citation que nous n'avons pas retrouvée, probablement inspirée soit de la préface de Charles Baudelaire aux Histoires extraordinaires d'A. E. Poe, soit au passage des Paradis artificiels, intitulé « Le poème du haschisch ». ${ }^{41}$ PANERO, Leopoldo María, Prueba de vida, Autobiografía de la muerte, Madrid, Huerga y Fierro editores, 2002, p. 47.

$42 A B C$, Gente y aparte, «El Golem», Samedi 13 mai 1989, p. 117.

43 PANERO, Leopoldo María, "Diario de un muerto en vida o la psicosis del zombie, Día 16 », in Prueba de vida, Autobiografía de la muerte, op. cit., p. 37.
} 
Ainsi tantôt le jardin se confond-il avec le monde, avec le lieu où se jouent la vie et la mort de chaque être, tantôt circonscrit-il l'espace carcéral dans lequel vivent et souffrent "ceux qui savent», par opposition aux "gens normaux», qui loin d'échapper au même sort, ne se différencient des exclus que par leur ignorance et une sorte de fausse liberté, qui ne les distinguent pas plus du golem que des reclus du jardin. Le jardin est un espace matérialisé soit par une frontière verticale - grille (los barrotes), porte (el loco mirando desde la puerta del jardín) ou murs (las paredes de mi cuarto) -, soit par une limite horizontale comme le suggère la cloaca superior d'où affleurent les êtres du monde d'en bas - las ratas afloran - vers le monde d'en haut.

Depuis cet espace qu'est le poème-jardin, le fou-poète lance cet avertissement au lecteur qui n'est pas sans rappeler l'« homme de bien... » ${ }^{44}$ auquel s'adresse Baudelaire.

\begin{abstract}
Hombre normal que por un momento
cruzas tu vida con la del esperpento

has de saber que no fue por matar al pelícano45

sino por nada por lo que yazgo aquí entre otros sepulcros

y que a nada sino al azar y a ninguna voluntad sagrada

de demonio o de dios debo mi ruina.
\end{abstract}

Leopoldo María Panero a chaque fois exercé sur celui à qui il s'adressait, sur celui qui l'approchait, comme sur le lecteur, une trouble fascination, nous renvoyant au cœur le plus ardent et le plus obscur du mystère de la vie et de la mort. Si l'on a pu parfois avoir le sentiment de toucher du doigt un mythe incarné - Golem ou poète maudit -, de côtoyer un voyant rimbaldien, une intelligence sans doute hors norme, douée d'une prodigieuse mémoire et dont la vie s'est tout entière consacrée à la lecture et à l'écriture, d'un damné dont on a du mal à décider s'il fut victime de la société ou de lui-même, c'est précisément parce que son œuvre brouille constamment les pistes. La figure du poète, la voix, qu'il a façonnées pour son lecteur, se présentent, comme celles d'un Peter Pan, éternel adolescent. En tant que tel, il s'adresse à l'adolescent, à l'homme révolté, que chacun de nous a tué en soi pour grandir, tout en se présentant en même temps comme la victime sacrificielle, le bouc émissaire d'une société qui ne le comprend pas. Semblable à l'albatros de Baudelaire, ou au pélican qui, dans la tradition des Pères de l'Église, alimente de son sang ses petits, il l'est l'homme-dieu qui nous convoque au Jardin des Oliviers, nous offre un masque qui par moments se fissure, pour faire entendre un rire rauque et sonore, et réduire à néant l'image qu'il s'est construite, comme dans le Jardín de los cerezos (la Cerisaie) de Tchekhov, dont Leopoldo María Panero rappelle la liquidation dans son premier recueil : A lo lejos se oyen golpes secos, uno tras otro los árboles se derrumban. Está en venta el jardín de los cerezos. ${ }^{46}$

\footnotetext{
${ }^{44}$ Baudelaire, Les Fleurs du Mal, "Épigraphe pour un livre condamné », in «Additions de la troisième édition des Fleurs du mal », op. cit., p. 193.

45 Allusion à Judas. Différents pères de l'Église, dont saint Eusèbe, saint Augustin et saint Isidore de Séville, ont vu une représentation du Christ dans le pélican qui se frappe les flancs avec ses ailes, pour en fait sortir du sang, le faire tomber dans son nid, et rendre ainsi la vie à ses petits.

46 PANERO, Leopoldo María, «Blancanieves se despide de los enanos » in Así se fundó Carnaby Street (1970), in Poesía 1970-1985, op. cit., p. 50.
} 